\title{
Diabetes and periprocedural outcomes in patients treated with rotablation during percutaneous coronary interventions
}

\author{
Rafał A. Januszek ${ }^{1,2}$, Artur Dziewierz ${ }^{2,3}$, Zbigniew Siudak ${ }^{4}$, Tomasz Rakowski ${ }^{2,3}$, \\ Jacek Legutko ${ }^{2,3}$, Łukasz Rzeszutko², Paweł Kleczyński², \\ Dariusz Dudek ${ }^{2,3,5}$, Stanisław Bartuś ${ }^{2,3}$ \\ ${ }^{1}$ Department of Clinical Rehabilitation, University of Physical Education, Krakow, Poland \\ ${ }^{2} 2^{\text {nd }}$ Department of Cardiology and Cardiovascular Interventions, University Hospital, Krakow, Poland \\ ${ }^{3} 2^{\text {nd }}$ Department of Cardiology, Jagiellonian University Medical College, Krakow, Poland \\ ${ }^{4}$ Faculty of Medicine and Health Sciences, Jan Kochanowski University, Kielce, Poland \\ ${ }^{5}$ Department of Interventional Cardiology, Jagiellonian University Medical College, Krakow, Poland
}

\begin{abstract}
Background: This study is to assess differences in periprocedural outcomes among diabetic and nondiabetic patients treated with percutaneous coronary intervention (PCI) and rotational atherectomy (RA). Methods: Under assessment were 221,187 patients from the Polish Cardiovascular Intervention Society national registry (ORPKI) including all PCIs performed in Poland in 2015 and 2016. Data was extracted of 975 patients treated with $R A-336$ (34.5\%) diabetics and 639 (65.5\%) non-diabetics. Periprocedural complications were defined as overall rate or particular complications such as deaths, no-reflows, perforations, dissections, cerebral strokes or bleedings. Multivariate analysis was performed to assess predictors of periprocedural complications.

Results: The mean age was similar in diabetics and non-diabetics $(70.9 \pm 9.0$ vs. $72.1 \pm 9.9 ; p=0.06)$. Diabetics were more often females ( $p<0.01)$, with arterial hypertension $(p<0.01)$, kidney failure $(p<0.01)$ and prior myocardial infarction $(p=0.01)$. No significant differences were observed in overall or individual periprocedural complications and angiographic success was expressed as thrombolysis in myocardial infarction grade 3 flow after PCI. At baseline, de-novo lesions accounted for $96.5 \%$ in diabetics and $99 \%$ in non-diabetics $(p<0.01)$, while overall rate of restenosis was $3.5 \%$ and $1 \%$, respectively $(p<0.01)$. Diabetes was an independent predictor of periprocedural complications in the overall group of patients treated with PCI (OR 1.11, 95\% CI 1.04-1.194; $p<0.001)$.

Conclusions: The negative impact of diabetes on the incidence of periprocedural complications and angiographic effectiveness in the group of patients treated with $R A$ is mitigated in the comparison to the non-RA group. (Cardiol J 2020; 27, 2: 152-161)
\end{abstract}

Key words: percutaneous coronary interventions, rotational atherectomy, periprocedural complications, angiographic effectiveness, in-stent restenosis, diabetics, predictors, coronary artery calcifications

\section{Introduction}

Diabetes mellitus (DM) is among leading risk factors for coronary atherosclerosis and is related to specific imaging of coronary arteries including disseminated atherosclerosis and narrowed coronary arteries [1,2]. Individuals with DM are also at increased risk of coronary artery calcifications (CAC) which is subsequently related to increased risk of cardiovascular events [3]. Patients with DM

Address for correspondence: Stanisław Bartuś, $\mathrm{MD}, \mathrm{PhD}, 2^{\text {nd }}$ Department of Cardiology, Jagiellonian University Medical College, ul. Kopernika 17, 31-501 Kraków, Poland, e-mail: stanislaw.bartus@uj.edu.pl 


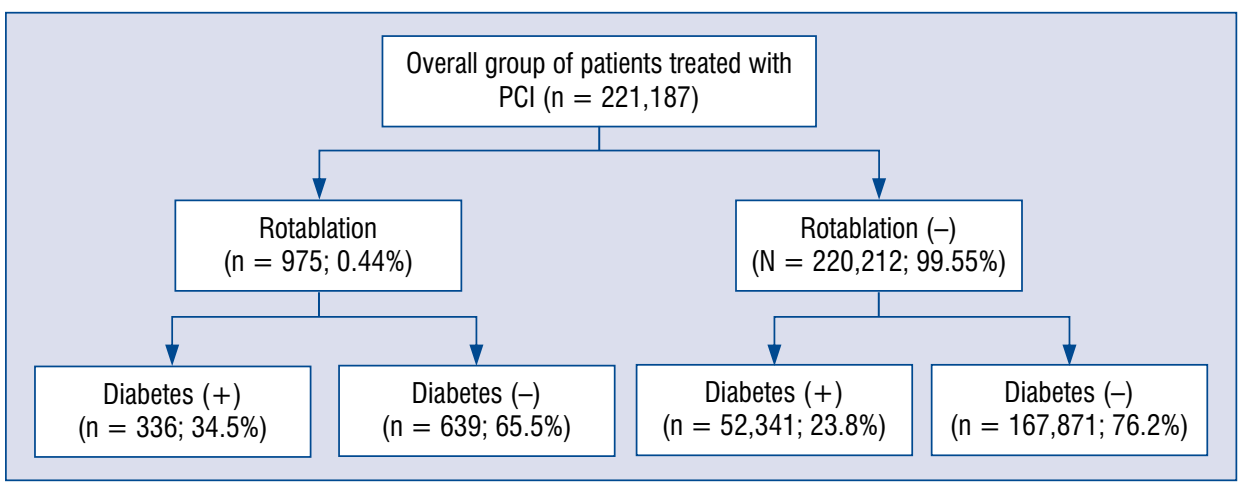

Figure 1. Patient flowchart.

undergoing coronary arteries revascularization with percutaneous coronary interventions (PCI) or coronary artery bypass grafting operations $(\mathrm{CABG})$ present higher restenosis and poorer longterm survival rates than non-diabetic patients [4]. The optimal method of revascularization for diabetic patients with disseminated atherosclerosis is a subject of constant debate. One of the methods of intravascular treatment which allows patients an option to avoid surgical revascularization is rotational atherectomy (RA). The results of previously published studies on groups of patients treated with PCI, not previously undergoing revascularization of coronary arteries, have provided inconclusive results. Despite differences in the angiographic images of the coronary arteries and the burden of accompanying diseases, some studies did not show differences in the efficacy and incidence of periprocedural complications between patients with and without diabetes, while the others showed a higher incidence of in-hospital deaths and nonfatal myocardial infarctions (MIs) $[5,6]$. The availability of recently published research on RA in the drugeluting stent (DES) era, comparing periprocedural outcomes depending on the prevalence of diabetes, is very limited. One of the very few older studies, comparing periprocedural results of $\mathrm{PCI}$ with plainold balloon angioplasty (POBA) preceded by RA in groups of patients with and without DM, revealed that initial success rate was comparable between those two groups [7]. Nonetheless, the complication rates were higher in non-diabetics compared to diabetics except for the need of dialysis or peripheral vascular complications.

Therefore, in the current study, the aim was to compare the angiographic effectiveness and complication rate in diabetics and non-diabetics treated with PCI and rotablation.

\section{Methods}

\section{Study population, design and definitions}

Data from all patients who underwent PCI in Poland between January 2015 and December 2016 were analyzed. Prospectively collected data on PCI practice in Poland were obtained from the ORPKI Polish national dataset, which is coordinated nationwide by Jagiellonian University Medical College in cooperation with the Association of Cardiovascular Interventions Polish Cardiac Society (AISN PTK). Database characteristics and data collection methods have previously been published [8-10]. Patients were categorized according to whether they were treated with RA and if they were diagnosed with diabetes or not. A flowchart of patients is presented in Figure 1. All indices recorded in the ORPKI database are based on periprocedural data uploaded by the operator after each procedure. Therefore, they do not include all in-hospital complications, mainly those which occurred after the procedure until discharge from the hospital. Also, follow-up data was not collected after discharge due to a lack of patient IDs. The decision to perform the RA procedure was at the operators' discretion at each center according to current European recommendations [11]. All clinical decisions, such as vascular access, thrombectomy, treatment with glycoprotein IIb/IIIa inhibitors or bivalirudin, were at the operators' discretion. The definition of periprocedural complications including death, perforation, dissection, allergic reaction, cerebral stroke, puncture site bleeding, no-reflow or cardiac arrest remained to the operators' personal preference and knowledge. The RA procedure was limited to one culprit artery, which was qualified for the procedure. Angiographic presentation refers to the general picture of coronary arteries. 


\section{Statistical analysis}

All continuous variables were evaluated with the Kolmogorov-Smirnov test for distribution. Continuous variables are presented as mean \pm standard deviation and median \pm interquartile range. Categorical variables are presented as numeric values and percentages. Continuous variables were compared using the two-tailed Student t-test and the Mann-Whitney U-test, whereas categorical variables using the $\chi^{2}$ test. Both, univariate and multivariate regression models for all complications were constructed in the group of patients treated with PCI but without RA. A model based on the retrograde correction method was created. Statistical significance was accepted at a 0.05 level of probability. The statistical analyses were performed using Statistica 10.0 software (Dell Software, Inc., Round Rock, TX, USA).

\section{Results}

\section{General characteristics}

The frequency of diabetes was higher in the group of patients treated with RA compared to those without RA (34.5\% vs. $23.8 \%$; $p<0.0001$; Fig. 1). The mean age was similar in diabetics and non-diabetics from the group of patients treated with RA $(70.9 \pm 9.0$ vs. $72.1 \pm 9.9 ; \mathrm{p}=0.06)$. Diabetics were more often women $(p=0.0008)$, those who suffered more often from arterial hypertension $(\mathrm{p}<0.0001)$, chronic kidney disease $(\mathrm{p}=0.004)$ and prior MI $(\mathrm{p}=0.01)$. Other concomitant diseases, previous cardiovascular interventions and smoking percentage did not differ significantly between groups. Also, the clinical presentation of coronary artery disease including stable angina, unstable angina, ST-segment elevation MI (STEMI), non-ST-segment elevation MI (NSTEMI) and others, did not differ between the diabetics and non-diabetics. Stable angina was more often a clinical presentation at baseline I patients treated with RA compared to the non-RA group. Also, patients treated with RA were previously more often treated due to coronary atherosclerosis and suffered from cardiac and cerebrovascular events. This is presented in Table 1.

\section{Pharmacotherapy}

Before admission to hospital, patients with diabetes were treated significantly more often with acetylsalicylic acid $(\mathrm{p}=0.001)$, clopidogrel $(\mathrm{p}=0.004)$ and ticagrelor $(\mathrm{p}<0.0001)$. Pharmacotherapy in patients from RA and non-RA group according to diabetes is presented in Table 2 .

\section{Procedural variables}

Vascular access and location of culprit lesion was according to the type of coronary artery or bypass graft were similar in both groups. Both PCI of chronic total occlusions lesions $(6.2 \%$ vs. $4.5 \%$, $\mathrm{p}=0.24)$ and bifurcations ( $11.6 \%$ vs. $6.2 \%)$ were performed more often in the group of diabetics in relation to non-diabetics, but only for bifurcations did it achieve statistical significance $(p=0.003)$. Single vessel disease was less frequent in diabetics compared to non-diabetics $(63.8 \%$ vs. $71.3 \%$, $\mathrm{p}=0.04)$, while multi-vessel disease with $(12.3 \%$ vs. $8.9 \%, \mathrm{p}=0.15)$ and without left-main coronary artery (LMCA) involvement (19.7\% vs. 17.8 ; $\mathrm{p}=0.53$ ), as well as separate LMCA involvement ( $4.1 \%$ vs. $1.9 \% ; \mathrm{p}=0.09$ ), occurred in all subgroups but more often in diabetics compared to non-diabetics, however, without statistical significance. Patients in RA group, in comparison to non-RA group were treated more often from femoral access, presented more often with more advanced atherosclerosis, were treated more often with DESs and underwent less often plain-old balloon angioplasty and/or failed angioplasty in both diabetics and nondiabetics. This is presented in Table 3.

\section{Culprit lesion characteristics}

Patients with DM, presented de-novo lesions significantly less often compared to non-diabetics at baseline $(96.5 \%$ vs. $99 \%, \mathrm{p}<0.01)$. De-novo lesions occurred significantly more often in patients from RA group compared to non-RA for diabetics and non-diabetics. However, diabetics presented restenosis significantly more frequently compared to non-diabetics at baseline (3.5\% vs. $1 \%$, $\mathrm{p}<0.0001$ ), and this was mostly due to higher DES restenosis rate (2\% vs. $0.4 \%, \mathrm{p}<0.0001)$. Also, the restenosis rate was higher in the group of patients treated without RA compared to the RA group for diabetics and non-diabetic. There were no patients treated due to in-stent thrombosis in patients treated with RA in diabetics and nondiabetics. This is presented in Figure $2 \mathrm{~A}-\mathrm{C}$.

\section{Angiographic effectiveness}

Angiographic effectiveness was expressed as thrombolysis in myocardial infarction (TIMI) 3 grade flow which was achieved after RA procedure. Despite the fact that a prevalence of patients with TIMI 3 grade flow prior to RA procedure was greater in diabetics $(62.9 \%$ vs. $51.7 \%, \mathrm{p}=0.0009)$, after treatment the TIMI 3 grade flow rate did not differ significantly between the two groups of patients treated with PCI and RA (97.3\% vs. 
Table 1. Patient characteristics.

\begin{tabular}{|c|c|c|c|c|c|c|}
\hline \multirow[t]{2}{*}{ Clinical variables } & \multicolumn{2}{|c|}{ RA (+) } & \multirow[t]{2}{*}{$\mathbf{P}$} & \multicolumn{2}{|c|}{ RA (-) } & \multirow[t]{2}{*}{$\mathbf{P}$} \\
\hline & Diabetes (+) & Diabetes (-) & & Diabetes (+) & Diabetes (-) & \\
\hline Age [years] & $\begin{array}{c}70.9 \pm 9.0 \\
70[65 \div 78]\end{array}$ & $\begin{array}{c}72.1 \pm 9.9 \\
73[65 \div 80]\end{array}$ & 0.06 & $\begin{array}{c}69 \pm 9.8 \\
69[62 \div 76]\end{array}$ & $\begin{array}{c}66.4 \pm 11^{*} \\
66[59 \div 75]\end{array}$ & $<0.001$ \\
\hline Gender (males) & $207(61.6 \%)$ & $461(72.1 \%)$ & $<0.001$ & $31,828(60.8 \%)$ & $117,644(70.1 \%)$ & $<0.001$ \\
\hline Hypertension & $299(89.0 \%)$ & $458(71.7 \%)$ & $<0.001$ & $45,589(86.9 \%)$ & $111,162(66.2 \%)^{*}$ & $<0.001$ \\
\hline Prior cerebral stroke & $17(5.0 \%)$ & $24(3.7 \%)$ & 0.33 & $2,993(5.7 \%)$ & $4,256(2.5 \%)$ & $<0.001$ \\
\hline Prior MI & $189(56.2 \%)$ & $309(48.3 \%)$ & 0.01 & $20,057(38.3 \%)^{*}$ & $48,400(28.8 \%)^{*}$ & $<0.001$ \\
\hline Prior $\mathrm{PCl}$ & $204(60.7 \%)$ & $364(57.0 \%)$ & 0.25 & $22,468(42.9 \%)^{*}$ & $59,408(35.4 \%)^{*}$ & $<0.001$ \\
\hline Prior CABG & $55(16.4 \%)$ & $92(14.4 \%)$ & 0.41 & $4,541(8.7 \%)^{*}$ & $9,404(5.6 \%)^{*}$ & $<0.001$ \\
\hline Smoking & $51(15.2 \%)$ & $88(13.8 \%)$ & 0.55 & $8,172(15.6 \%)$ & $34,268(20.4 \%)^{*}$ & $<0.001$ \\
\hline Psoriasis & $1(0.3 \%)$ & $0(0 \%)$ & 0.16 & $299(0.57 \%)$ & $569(0.3 \%)$ & $<0.001$ \\
\hline Kidney failure & $51(15.2 \%)$ & $58(9.1 \%)$ & 0.004 & $5,686(10.9 \%)^{*}$ & 6,332 (3.8\%) & $<0.001$ \\
\hline COPD & $11(3.3 \%)$ & $18(2.8 \%)$ & 0.68 & $2,030(3.87 \%)$ & $9,404(5.6 \%)^{*}$ & $<0.001$ \\
\hline \multicolumn{7}{|c|}{ Clinical presentation before $\mathrm{PCl}$ : } \\
\hline Stable angina & $178(53.3 \%)$ & $352(55.7 \%)$ & 0.47 & $15,828(30.3 \%)^{*}$ & $44,694(26.7 \%)^{*}$ & $<0.001$ \\
\hline Unstable angina & $70(20.9 \%)$ & $117(18.5 \%)$ & 0.36 & $16,124(30.8 \%)^{*}$ & $49,406(29.5 \%)^{*}$ & $<0.001$ \\
\hline NSTEMI & $39(11.7 \%)$ & $73(11.5 \%)$ & 0.95 & $10,557(20.2 \%)^{*}$ & $30,447(18.2 \%)^{*}$ & $<0.001$ \\
\hline STEMI & $45(13.5 \%)$ & $88(13.9 \%)$ & 0.84 & $9,361(17.9 \%)^{*}$ & $41,620(24.8 \%)^{*}$ & $<0.001$ \\
\hline Others & $2(0.6 \%)$ & $2(0.3 \%)$ & 0.51 & $412(0.8 \%)$ & $1,441(0.8 \%)$ & 0.11 \\
\hline
\end{tabular}

Data are expressed as mean \pm standard deviation and median $\div$ interquartile range or numbers (percentages). The Student's t-test was used for continuous variables and the $\chi^{2}$ test was used for categorical variables; ${ }^{*} \mathrm{p}<0.05$, when particular variable in rotational atherectomy (RA) group differs from corresponding in non-RA group; CABG - coronary artery bypass grafting surgery; COPD - chronic obstructive pulmonary disease; $\mathrm{MI}$ - myocardial infarction; NSTEMI - non-ST-segment elevation myocardial infarction; $\mathrm{PCl}$ - percutaneous coronary intervention; STEMI - ST-segment elevation myocardial infarction

Table 2. Pharmacotherapy.

\begin{tabular}{|c|c|c|c|c|c|c|}
\hline \multirow[t]{2}{*}{ Pharmacotherapy } & \multicolumn{2}{|c|}{$\mathbf{R A}(+)$} & \multirow[t]{2}{*}{$\mathbf{P}$} & \multicolumn{2}{|c|}{ RA (-) } & \multirow[t]{2}{*}{$\mathbf{P}$} \\
\hline & Diabetes (+) & Diabetes (-) & & Diabetes (+) & Diabetes (-) & \\
\hline \multicolumn{7}{|c|}{ Before hospitalization } \\
\hline Acetylsalicylic acid & $143(42.5 \%)$ & $204(31.9 \%)$ & 0.001 & $26,006(49.7 \%)^{*}$ & $82,020(48.8 \%)^{*}$ & 0.001 \\
\hline \multicolumn{7}{|l|}{ P2Y12 inhibitors: } \\
\hline clopidogrel & $154(45.8 \%)$ & $233(36.5 \%)$ & 0.004 & $29,754(56.8 \%)^{*}$ & $91,664(54.6 \%)^{*}$ & $<0.001$ \\
\hline ticagrelor & $5(1.5 \%)$ & $9(1.4 \%)$ & $<0.001$ & $2,454(4.7 \%)^{*}$ & $8,666(5.2 \%)^{*}$ & $<0.001$ \\
\hline prasugrel & $1(0.3 \%)$ & $0(0 \%)$ & 0.16 & $275(0.5 \%)$ & $889(0.5 \%)$ & 0.9 \\
\hline GP IIb/IIla inhibitors & $4(3.0 \%)$ & $13(5.3 \%)$ & 0.31 & $4,156(9.7 \%)^{*}$ & $17,330(12.5 \%)^{*}$ & $<0.001$ \\
\hline Bivalirudin & $0(0 \%)$ & $0(0 \%)$ & - & $4(0.007 \%)$ & $13(0.007 \%)$ & 0.98 \\
\hline \multicolumn{7}{|l|}{ During $\mathrm{PCl}$} \\
\hline Acetylsalicylic acid & $244(72.6 \%)$ & $424(66.3 \%)$ & 0.04 & $9,174(17.5 \%)^{*}$ & $27,712(16.5 \%)^{*}$ & $<0.001$ \\
\hline \multicolumn{7}{|l|}{ P2Y12 inhibitors: } \\
\hline clopidogrel & $149(44.3 \%)$ & $252(39.4 \%)$ & 0.13 & $21.881(41.8 \%)$ & $70,803(42.2 \%)$ & 0.13 \\
\hline ticagrelor & $11(3.3 \%)$ & $37(5.8 \%)$ & 0.08 & $2.475(4.7 \%)$ & $7,836(4.7 \%)$ & 0.56 \\
\hline prasugrel & $0(0 \%)$ & $1(0.1 \%)$ & 0.46 & $240(0.4 \%)$ & $765(0.45 \%)$ & 0.93 \\
\hline GP Ilb/IIla inhibitors & $1(0.3 \%)$ & $6(0.9 \%)$ & 0.25 & $164(0.31 \%)$ & $678(0.4 \%)^{*}$ & 0.003 \\
\hline Bivalirudin & $1(0.3 \%)$ & $2(0.3 \%)$ & 0.96 & $132(0.25 \%)$ & $435(0.26 \%)$ & 0.78 \\
\hline
\end{tabular}

Data are expressed as numbers (percentages). The $\chi^{2}$ test was used for categorical variables; ${ }^{*} p<0.05$, when particular variable in rotational atherectomy (RA) group differs from corresponding in non-RA group; GP — glycoprotein; $\mathrm{PCl}$ - percutaneous coronary intervention 


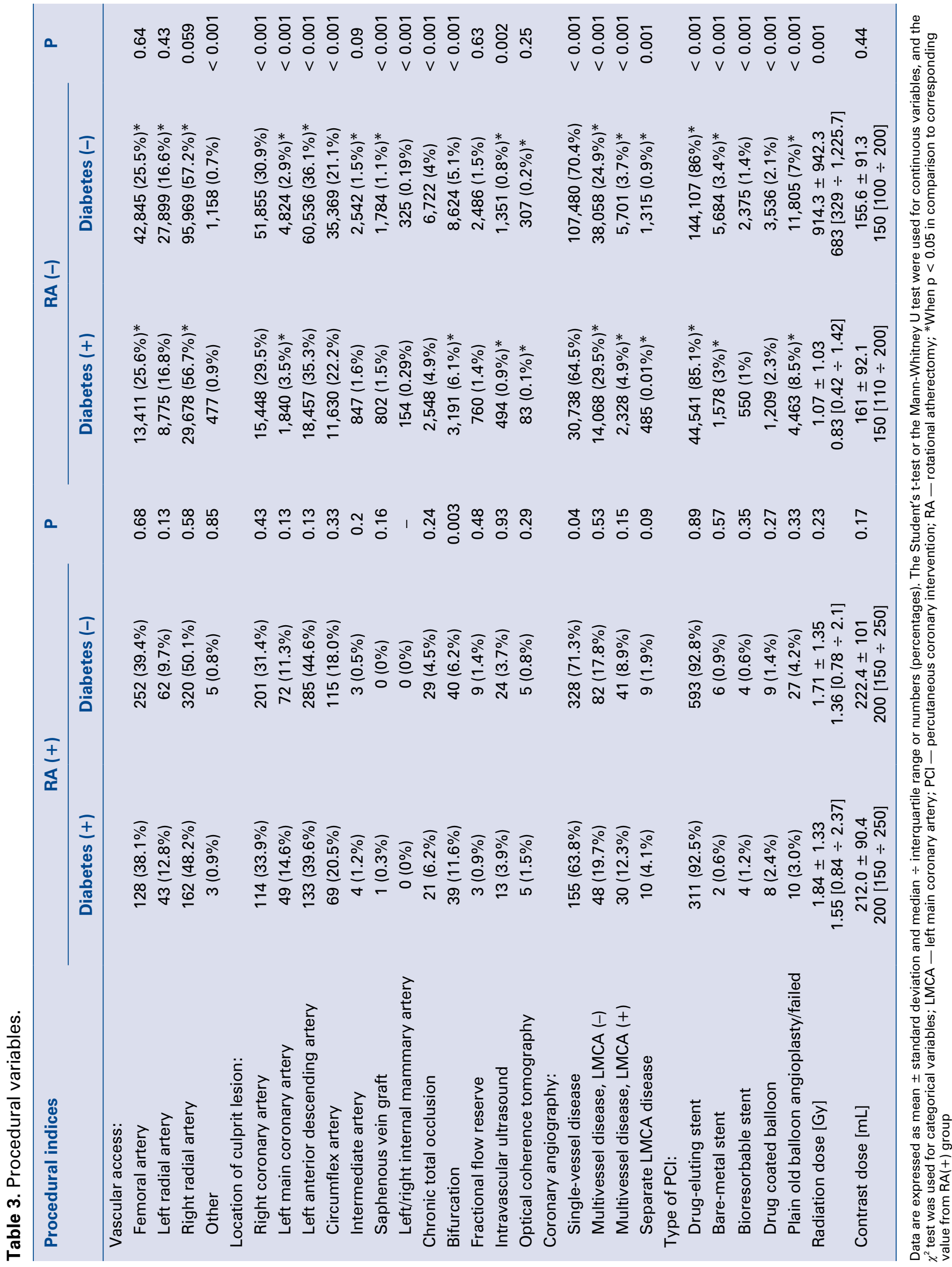




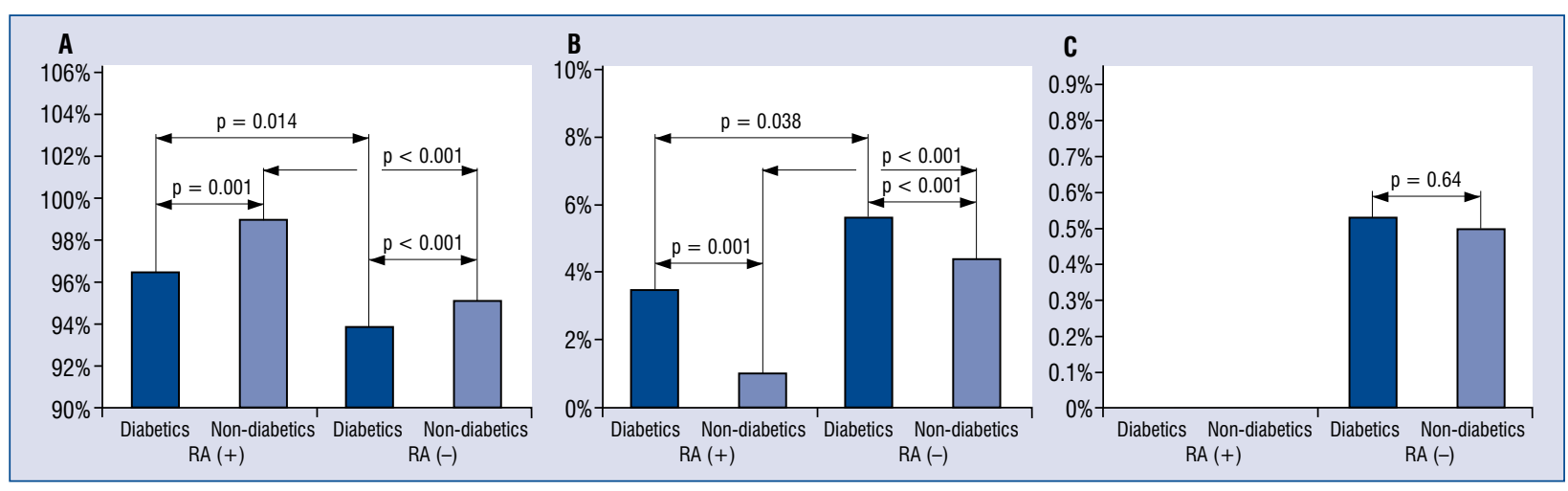

Figure 2. A. The frequency of de-novo lesions in rotational atherectomy (RA) and non-RA group according to diabetes status before the procedure; B. The frequency of overall restenosis in RA and non-RA group according to diabetes status before the procedure; $\mathbf{C}$. The frequency of in-stent thrombosis in RA and non-RA group according to diabetes status before the procedure.

Table 4. Angiographic effectiveness.

\begin{tabular}{|c|c|c|c|c|c|c|}
\hline \multirow[t]{2}{*}{ TIMI grade flow } & \multicolumn{2}{|c|}{ At baseline } & \multirow[t]{2}{*}{$\mathbf{P}$} & \multicolumn{2}{|c|}{ After $\mathrm{PCl}$} & \multirow[t]{2}{*}{$\mathbf{P}$} \\
\hline & Diabetes (+) & Diabetes (-) & & Diabetes (+) & Diabetes (-) & \\
\hline \multicolumn{7}{|c|}{$\mathrm{PCl}$ with rotablation } \\
\hline 0 & $27(8.1 \%)$ & $43(7.0 \%)$ & $<0.001$ & $3(0.9 \%)$ & $2(0.3 \%)$ & 0.51 \\
\hline 1 & $35(10.5 \%)$ & $104(16.9 \%)$ & & $1(0.3 \%)$ & $4(0.6 \%)$ & \\
\hline 2 & $61(18.4 \%)$ & $150(24.4 \%)$ & & $5(1.5 \%)$ & $13(2.1 \%)$ & \\
\hline 3 & $209(62.9 \%)$ & $318(51.7 \%)$ & & $324(97.3 \%)^{*}$ & $605(96.9 \%)^{*}$ & \\
\hline \multicolumn{7}{|c|}{$\mathrm{PCl}$ without rotablation } \\
\hline 0 & $8,928(17.6 \%)$ & $35,559(22.1 \%)$ & $<0.001$ & $1,336(2.6 \%)$ & $3,528(2.2 \%)$ & $<0.001$ \\
\hline 1 & $6,339(12 \%)$ & $22,246(13.8 \%)$ & & $585(1.1 \%)$ & $1,587(1 \%)$ & \\
\hline 2 & $9,748(19.2 \%)$ & $30,379(18.8 \%)$ & & $1,491(2.9 \%)$ & $4,282(2.6 \%)$ & \\
\hline 3 & $25,650(50.6 \%)^{\#}$ & $72,938(45.2 \%)^{\#}$ & & $47,287(93.3 \%)^{*}$ & $151,791(94.2 \%)^{*}$ & \\
\hline
\end{tabular}

Data are expressed as numbers (percentages). The $\chi^{2}$ test was used for categorical variables; ${ }^{*} p<0.05$, when the results of TIMI flow differs after PCl from that before $\mathrm{PCl}$ in diabetics and non-diabetics; $\# \mathrm{p}<0.05$, when the results of TIMI flow differs between rotational atherectomy (RA) and non-RA group in corresponding groups assessed before and after $\mathrm{PCl}$; $\mathrm{TIMI}$ - thrombolysis in myocardial infarction; PCl — percutaneous coronary intervention

$96.9 \%, \mathrm{p}=0.76)$. However, it was higher when compared to the non-RA group of diabetics $(97.3 \%$ vs. $93.3 \%, \mathrm{p}=0.003)$ and non-diabetics $(96.9 \%$ vs. $94.2 \%, p=0.003)$. However, when compared with contingency tables, the distribution of TIMI classes after endovascular treatment was not significantly different between the group of patients treated with RA or without RA ( $p=0.23$ for non-diabetics and $\mathrm{p}=0.11)$. This is presented in Table 4 .

\section{Periprocedural complications}

The overall complication rate did not differ significantly between diabetics and non-diabetics, in the RA group ( $2.38 \%$ vs. $2.34 \%, \mathrm{p}=0.97$ ). It also did not differ between groups for particular complications in the RA group: coronary artery per- foration ( $1.2 \%$ vs. $0.8 \% ; \mathrm{p}=0.52)$, cardiac arrest $(0.6 \%$ vs. $0.6 \% ; \mathrm{p}=0.95)$, allergic reaction $(0.3 \%$ vs. $0.1 \% ; \mathrm{p}=0.64)$, no-reflow $(0.3 \%$ vs. $0.8 \%$; $\mathrm{p}=0.35)$ or puncture site bleeding $(0.3 \%$ vs. $0.1 \%$; $\mathrm{p}=0.64)$. The overall complication rate was lower in the non-RA group compared to the RA group for diabetics (2.34 vs. $2.14, \mathrm{p}=0.36)$ and non-diabetics ( $2.38 \%$ vs. $1.85 \%, \mathrm{p}=0.76)$. Moreover, the overall complication rate was significantly higher in diabetics compared to non-diabetics in the non-RA group of patients (2.14 vs. $1.85, \mathrm{p}<0.0001)$. This is presented in Figure 3. Among independent predictors of an increased rate of overall complication in the group of patients treated with PCI without RA, it was thus found: diabetes (odds ratio [OR] 1.11, 95\% confidence interval [CI] 1.04-1.194; 


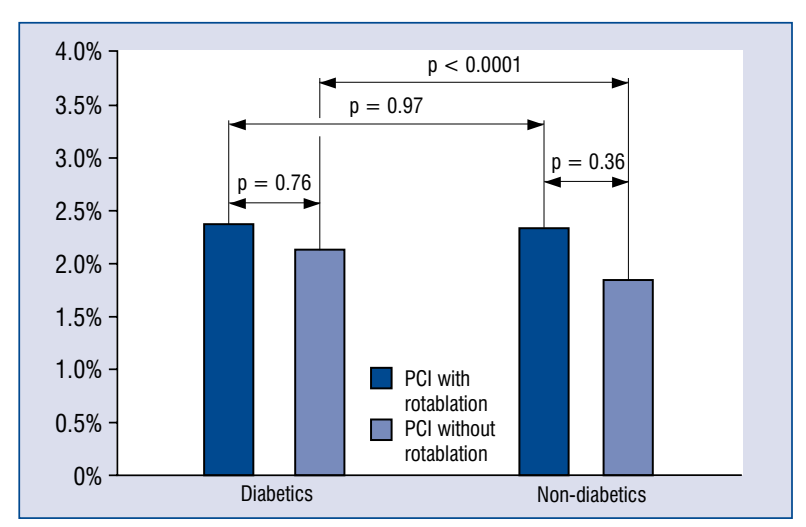

Figure 3. The overall periprocedural complication rate in the rotational atherectomy (RA) and non-RA groups according to diabetes status; $\mathrm{PCl}$ - percutaneous coronary intervention.

$\mathrm{p}<0.001$ ), age (OR 1.02, 95\% CI 1.01-1.02; $\mathrm{p}<0.001)$, female gender (OR $1.28,95 \% \mathrm{CI}$ $1.12-1.3 ; \mathrm{p}<0.001)$, prior MI (OR $1.31,95 \% \mathrm{CI}$ $1.21-1.43 ; \mathrm{p}<0.001)$, prior cerebral stroke (OR $1.67,95 \%$ CI $1.47-1.91 ; \mathrm{p}<0.001)$, kidney failure (OR 1.61, 95\% CI 1.44-1.81; $\mathrm{p}<0.001$ ), acute coronary syndrome (OR 1.659, 95\% CI 1.151-1.817, $\mathrm{p}<0.001$ ) and psoriasis (OR 1.54, 95\% CI 1.04-2.28; $\mathrm{p}=0.04$ ), while among predictors of decreased rate of procedural related complications patent culprit artery before PCI was noticed (OR 0.39, 95\% CI $0.37-0.42 ; \mathrm{p}<0.001)$ as well as a hypertension (OR 0.93, 95\% CI 0.86-0.99; $\mathrm{p}<0.05$ ).

\section{Discussion}

The main finding of the current study is that patients with DM treated with PCI and RA presents comparable periprocedural complication rates and angiographic success compared to patients without DM. While in the overall group of patients treated with PCI without RA, diabetics treated present poorer angiographic success and greater rate of periprocedural complications. Comparing outcomes of DM patients in cases of PCI without RA and PCI with RA, it can be concluded that RA attenuates the negative impact of DM on the increased rate of periprocedural complications and poorer angiographic outcomes. Also, the rate of successful PCI assessed as the percentage of POBA and/ /or failed PCI was significantly higher in the group of patients treated without RA compared to those treated with RA for diabetics and non-diabetics. Moreover, while in the group of non-RA patients PCI success expressed as POBA/failed PCI rate was significantly poorer in diabetics, in patients treated with RA it was poorer for non-diabetics.

It has been almost 40 years since interventional cardiologists began to be interested in factors affecting the results of RA treatment [12]. Currently, around $20 \%$ of patients referred for revascularization procedures are diabetics. Because of current knowledge, CABG is treatment superior to $\mathrm{PCI}$ in patients with $\mathrm{DM}$ and advanced coronary artery disease, and is related to decreased risk of death and MI [13]. PCI is a potential treatment option in patients with less complex lesions [14]. It has been demonstrated that patients treated with PCI and DES present a significant reduction in target lesion revascularization when compared to PCI with bare metal stent [15]. Most of the published studies demonstrate that diabetes is also associated with an increased incidence of CAC and thrombus $[3,16]$. Also, a large meta-analysis including 12,682 patients has proven that DM and hypertension predict the presence and extent of CAC in symptomatic patients [17]. However, not all authors demonstrated that DM is associated with increased CAC. For example, with the use of optical coherence tomography, Milzi et al. [18] revealed that decreased fibrous cup thickness overlying the necrotic lipid core, rather than $\mathrm{CAC}$, contributes to increased plaque vulnerability observed in diabetics. While some studies have shown that calcified nodules are among the least common etiology of plaque erosions in patients with acute coronary syndromes, a majority of them have demonstrated that patients with CAC treated with regular PCI belong to the group at significantly increased risk of adverse cardiovascular events in the follow-up period, especially other acute coronary syndromes $[19,20]$. Patients with CACs are also at increased risk of stent thrombosis and ischemic target lesion revascularization at year 1 , and remain at increased ischemic risk, irrespective of new generation DES $[21,22]$.

In the current study, the frequency of diabetes in the group of patients treated with RA was significantly higher when compared to those treated with PCI but without RA (34.5\% vs. $23.8 \%$, $\mathrm{p}<0.0001)$. Similarly, the incidence of other comorbidities and women was higher in diabetics compared to non-diabetics and was higher in patients treated with RA compared to non-RA. The obvious consequence of this is a lower incidence of patients with single disease in favor of patients with multi-vessel disease and LMCA involvement in diabetics compared to non-diabetics. A similar relationship was observed for comparison between 
RA and non-RA group of patients. What is more, diabetic patients treated with PCI with RA had statistically significantly lower incidences of denovo lesions and higher frequencies of restenosis at baseline. In a previous publication, it was also confirmed that diabetes is an independent predictor of restenosis in an overall group of patients treated with PCI [23]. Due to the fact that a percentage of patients with diabetes in the subgroup of RA patients was higher, this relationship was preserved. However, in the current study, a lower rate of restenosis in patients formed the RA group compared to the non-RA group and was related to a higher rate of de-novo lesions for both diabetics and non-diabetics.

Despite all the above listed risk factors of cardiovascular events related to diabetes, the incidence of overall periprocedural complications in the group of patients treated with PCI and RA was slightly greater in diabetics compared to non-diabetics and it did not reach statistical significance. Nonetheless, in the group of patients treated with PCI without RA the negative effect of diabetes translated into a significantly increased rate of periprocedural complications and poorer angiographic effectiveness. An increased rate of periprocedural complications has been reported in patients with $\mathrm{CAC}$, to which diabetes predisposes [24]. A higher frequency of periprocedural complications in the group of patients treated with PCI and RA in comparison to the group of patients treated with PCI without RA is not surprising, and it is the consequence of a number of factors such as RA itself, a selected group of patients with advanced atherosclerosis, which is usually a consequence of exposure to a larger number of risk factors for atherosclerosis. The frequency alignment of overall periprocedural complications in the RA group between diabetics and non-diabetics may, at least to some extent, be a consequence of a greater use of acetylsalicylic acid and P2Y12 inhibitors before the procedure in diabetics, which may contribute to reducing the number of no-reflows, cardiac arrests and deaths.

Another, rather more influential factor seems to be RA as a procedure. The increased frequency of periprocedural complications and poorer angiographic efficacy in patients with DM and CAC is mostly derived by difficulties with stent delivery, expansion, increased rate of coronary artery dissections, perforations, no-reflows and following cardiac arrests, cerebral strokes and deaths, as well as puncture site bleedings. The RA procedure itself decreases the risk of culprit artery related complications and systemic complications result- ing from them. This is followed by the fact that passages performed with a rotablator during the procedure decreases the amount of calcified debris and widens the artery lumen [11]. This permits, among others, easier delivery of the stent and its better expansion, while reducing the number of complications. On the other hand, it was shown that RA is associated with a greater frequency of coronary perforations, but this factor occurred in both of the groups compared [8].

The results of previously published studies regarding the relationship between diabetes with acute results of PCI indicate an insignificantly lower incidence of periprocedural complications assessed as at least one major complication (death, MI, emergency bypass surgery or abrupt closure) in the group of diabetics compared to non-diabetics in patients treated with PCI and RA. This number is insignificantly higher in the case of diabetics compared to non-diabetics in the non-RA group [7]. Furthermore, long term results were poorer for diabetics in RA and non-RA patients [7]. Similar acute results were obtained in the present work, where the overall periprocedural complication rate was greater in diabetics compared to non-diabetics in non-RA patients. Additionally, diabetes was also found to be an independent predictor of periprocedural complications in the non-RA group. This difference disappears and ceases to be statistically significant in the population of patients treated with PCI and RA. A similar relationship of DM and outcomes of RA treatment was presented in the analysis published by Mak and Faxon [25]. They underlined no significant influence of diabetes on periprocedural complication rate in patients treated with RA, however, they found at least some evidence of a negative effect of diabetes on clinical outcomes during follow-up in patients treated with PCI and PCI with RA [26]. Whereas in-hospital adverse outcomes, long-term mortality and the need for repeat revascularization procedures were reported in the era of POBA to be higher among diabetics [27, 28]. In the years of the initial experiments, when the only treatment method was POBA, the results for diabetics were significantly worse, while the current primary treatment method is PCI followed by DES implantation, which can affect the gap between diabetics and non-diabetics. Nevertheless, more recently published analysis also depicts the strong effect of diabetes on restenosis rate in patients after PCI [15, 29].

In the presented study, the angiographic effectiveness assessed as the percentage of patients with patent coronary artery after PCI (TIMI 3 
grade flow) was similar in diabetics compared to non-diabetics in patients treated with PCI and RA. Similar results have been published previously by other authors. Despite visible differences in the mean age, gender, the severity of coronary atherosclerosis and concomitant diseases, procedural success rates were comparable between patients with and without DM [27, 28]. In the current study, the procedural effectiveness was significantly lower for both diabetics and non-diabetics in the nonRA group compared to the RA group. Moreover, diabetics from the non-RA group, as in the case of periprocedural complications, presented lower procedural effectiveness when compared to nondiabetics. There are several reasons which can be attributed to the cause of those differences. One of the reasons is that the group of patients treated with PCI but without RA included chronic total occlusions, while patients in the group treated with RA included selected patients, where it was possible to cross the lesions with a rotawire. This is reflected in the percentage share of patients qualified for PCI procedures, where the percentage of patients with an occluded vessel (TIMI 1 and 2) was significantly larger, both for diabetics and non-diabetics in the non-RA group compared to the RA group. Moreover, as mentioned above, due to burr passages, the RA itself widens coronary artery lumen enabling better stent expansion, which undoubtedly improves the angiographic effectiveness.

\section{Limitations of the study}

First of all, this study was based on the nationwide volunteer registry rather than a prospective randomized clinical trial. This tends to decrease and underestimate the detection of periprocedural complication rate and other crucial variables which are dependent on a subjective assessment of an operator, despite the large overall interventional volume included in the present analysis. Also, the assessment of blood flow in the target artery using the TIMI scale is subjective and depends on individual operators, despite the fact that a large number of procedures can significantly reduce this effect. Furthermore, the current analysis does not include all in-hospital complications, which certainly weakens its value. Nonetheless, the uncountable advantage of the current study is that the results are closer to real life rather than to randomized clinical trials and show clinical data depicting the results of RA in diabetics in Central Europe.

\section{Conclusions}

The negative impact of diabetes on the incidence of periprocedural complications and angiographic effectiveness in the group of patients treated with RA is mitigated in comparison to the non-RA group.

\section{Conflict of interest: None declared}

\section{References}

1. Kannel WB, McGee DL. Diabetes and cardiovascular disease. The Framingham study. JAMA. 1979; 241(19): 2035-2038, indexed in Pubmed: 430798.

2. Vigorito C, Betocchi S, Bonzani G, et al. Severity of coronary artery disease in patients with diabetes mellitus. Angiographic study of 34 diabetic and 120 nondiabetic patients. Am Heart J. 1980; 100(6 Pt 1): 782-787, indexed in Pubmed: 7446380.

3. Wong ND, Nelson JC, Granston T, et al. Metabolic syndrome, diabetes, and incidence and progression of coronary calcium: the Multiethnic Study of Atherosclerosis study. JACC Cardiovasc Imaging. 2012; 5(4): 358-366, doi: 10.1016/j.jcmg.2011.12.015, indexed in Pubmed: 22498324.

4. Niles NW, McGrath PD, Malenka D, et al. Northern New England Cardiovascular Disease Study Group. Survival of patients with diabetes and multivessel coronary artery disease after surgical or percutaneous coronary revascularization: results of a large regional prospective study. Northern New England Cardiovascular Disease Study Group. J Am Coll Cardiol. 2001; 37(4): 1008-1015, indexed in Pubmed: 11263600.

5. Stein B, Weintraub WS, Gebhart SP, et al. Influence of diabetes mellitus on early and late outcome after percutaneous transluminal coronary angioplasty. Circulation. 1995; 91(4): 979-989, indexed in Pubmed: 7850985.

6. Kip KE, Faxon DP, Detre KM, et al. Coronary angioplasty in diabetic patients. The National Heart, Lung, and Blood Institute Percutaneous Transluminal Coronary Angioplasty Registry. Circulation. 1996; 94(8): 1818-1825, indexed in Pubmed: 8873655.

7. Levine G, Jacobs A, Keeler G, et al. Impact of Diabetes Mellitus on Percutaneous Revascularization (CAVEAT-I). Am J Cardiol. 1997; 79(6): 748-755, doi:10.1016/s0002-9149(96)00862-4.

8. Januszek R, Siudak Z, Dziewierz A, et al. Predictors of in-hospital effectiveness and complications of rotational atherectomy (from the ORPKI Polish National Registry 2014-2016). Catheter Cardiovasc Interv. 2017 [Epub ahead of print], doi: 10.1002/ ccd.27372, indexed in Pubmed: 29068164.

9. Siudak Z, Tokarek T, Dziewierz A, et al. Reduced periprocedural mortality and bleeding rates of radial approach in ST-segment elevation myocardial infarction. Propensity score analysis of data from the ORPKI Polish National Registry. EuroIntervention. 2017; 13(7): 843-850, doi: 10.4244/EIJ-D-17-00078, indexed in Pubmed: 28606891.

10. Rzeszutko E, Tokarek T, Siudak $Z$, et al. Patient profile and periprocedural outcomes of bioresorbable vascular scaffold implantation in comparison with drug-eluting and bare-metal stent implantation. Experience from ORPKI Polish National Registry 
2014-2015. Postepy Kardiol Interwencyjnej. 2016; 12(4): 321-328, doi: 10.5114/aic.2016.63632, indexed in Pubmed: 27980545.

11. Barbato E, Carrié D, Dardas P, et al. European Association of Percutaneous Cardiovascular Interventions. European expert consensus on rotational atherectomy. EuroIntervention. 2015; 11(1): 30-36, doi: 10.4244/EIJV11I1A6, indexed in Pubmed: 25982648.

12. Teirstein PS, Warth DC, Haq N, et al. High speed rotational coronary atherectomy for patients with diffuse coronary artery disease. J Am Coll Cardiol. 1991; 18(7): 1694-1701, indexed in Pubmed: 1960315.

13. Farkouh ME, Domanski M, Sleeper LA, et al. FREEDOM Trial Investigators. Strategies for multivessel revascularization in patients with diabetes. N Engl J Med. 2012; 367(25): 2375-2384, doi: 10.1056/NEJMoa1211585, indexed in Pubmed: 23121323.

14. Mack MJ, Banning AP, Serruys PW, et al. Bypass versus drug-eluting stents at three years in SYNTAX patients with diabetes mellitus or metabolic syndrome. Ann Thorac Surg. 2011; 92(6): 2140-2146, doi: 10.1016/j.athoracsur.2011.06.028, indexed in Pubmed: 21967819.

15. Bangalore S, Kumar S, Fusaro M, et al. Outcomes with various drug eluting or bare metal stents in patients with diabetes mellitus: mixed treatment comparison analysis of 22,844 patient years of follow-up from randomised trials. BMJ. 2012; 345: e5170, doi: 10.1136/bmj.e5170, indexed in Pubmed:22885395.

16. Kato K, Yonetsu T, Kim SJ, et al. Comparison of nonculprit coronary plaque characteristics between patients with and without diabetes: a 3-vessel optical coherence tomography study. JACC Cardiovasc Interv. 2012; 5(11): 1150-1158, doi: 10.1016/j. jcin.2012.06.019, indexed in Pubmed: 23174639.

17. Nicoll R, Zhao Y, Ibrahimi P, et al. Diabetes and hypertension consistently predict the presence and extent of coronary artery calcification in symptomatic patients: a systematic review and meta-analysis. Int J Mol Sci. 2016; 17(9): 1481, doi: 10.3390/ ijms17091481, indexed in Pubmed: 27608015.

18. Milzi A, Burgmaier M, Burgmaier K, et al. Type 2 diabetes mellitus is associated with a lower fibrous cap thickness but has no impact on calcification morphology: an intracoronary optical coherence tomography study. Cardiovasc Diabetol. 2017; 16(1): 152, doi: 10.1186/s12933-017-0635-2, indexed in Pubmed: 29195505.

19. Jia $\mathrm{H}$, Abtahian $\mathrm{F}$, Aguirre $\mathrm{AD}$, et al. In vivo diagnosis of plaque erosion and calcified nodule in patients with acute coronary syndrome by intravascular optical coherence tomography. J Am Coll Cardiol. 2013; 62(19): 1748-1758, doi: 10.1016/j. jacc.2013.05.071, indexed in Pubmed: 23810884.

20. Zimoch WJ, Kubler P, Kosowski M, et al. Patients with acute myocardial infarction and severe target lesion calcifications un- dergoing percutaneous coronary intervention have poor longterm prognosis. Kardiol Pol. 2017; 75(9): 859-867, doi: 10.5603/ KP.a2017.0093, indexed in Pubmed: 28541597.

21. Giustino G, Mastoris I, Baber U, et al. Correlates and Impact of Coronary Artery Calcifications in Women Undergoing Percutaneous Coronary Intervention With Drug-Eluting Stents: From the Women in Innovation and Drug-Eluting Stents (WIN-DES) Collaboration. JACC Cardiovasc Interv. 2016; 9(18): 1890-1901, doi: 10.1016/j.jcin.2016.06.022, indexed in Pubmed: 27659564.

22. Généreux P, Madhavan MV, Mintz GS, et al. Ischemic outcomes after coronary intervention of calcified vessels in acute coronary syndromes. Pooled analysis from the HORIZONS-AMI (Harmonizing Outcomes With Revascularization and Stents in Acute Myocardial Infarction) and ACUITY (Acute Catheterization and Urgent Intervention Triage Strategy) TRIALS. J Am Coll Cardiol. 2014; 63(18): 1845-1854, doi: 10.1016/j.jacc.2014.01.034, indexed in Pubmed: 24561145.

23. Januszek R, Siudak Z, Dziewierz A, et al. Chronic obstructive pulmonary disease affects the angiographic presentation and outcomes of patients with coronary artery disease treated with percutaneous coronary interventions. Pol Arch Intern Med. 2018; 128(1): 24-34, doi: 10.20452/pamw.4145, indexed in Pubmed: 29112944.

24. Fitzgerald PJ, Ports TA, Yock PG. Contribution of localized calcium deposits to dissection after angioplasty. An observational study using intravascular ultrasound. Circulation. 1992; 86(1): 64-70, indexed in Pubmed: 1617791.

25. Mak KH, Faxon DP. Clinical studies on coronary revascularization in patients with type 2 diabetes. Eur Heart J. 2003; 24(12): 1087-1103, indexed in Pubmed: 12804923.

26. Kishi K, Hiasa Y, Ogata T, et al. Comparison of results of rotational atherectomy for diffuse coronary artery disease in diabetics versus nondiabetics. Am J Cardiol. 2001; 87(7): 894-896, indexed in Pubmed: 11274947.

27. Stein B, Weintraub WS, Gebhart SP, et al. Influence of diabetes mellitus on early and late outcome after percutaneous transluminal coronary angioplasty. Circulation. 1995; 91(4): 979-989, indexed in Pubmed: 7850985.

28. Kip KE, Faxon DP, Detre KM, et al. Coronary angioplasty in diabetic patients. The National Heart, Lung, and Blood Institute Percutaneous Transluminal Coronary Angioplasty Registry. Circulation. 1996; 94(8): 1818-1825, indexed in Pubmed: 8873655.

29. Orbach A, Halon DA, Jaffe R, et al. Impact of diabetes and early revascularization on the need for late and repeat procedures. Cardiovasc Diabetol. 2018; 17(1): 25, doi: 10.1186/s12933-0180669-0, indexed in Pubmed: 29402330. 